\title{
ACUERDO CERRADO - (DES)CONSTRUINDO O DIS- CURSO UTILITARISTA SOBRE A APRENDIZAGEM DA LÍNGUA ESPANHOLA
}

\section{ACUERDO CERRADO - (DE)CONSTRUCTING THE UTILITARIAN DISCOURSE ABOUT LEARNING SPANISH AS A FOREIGN LANGUAGE}

\author{
Fernando Zolin-Vesz \\ Flavia Braga Krauss de Vilhena
}

\section{RESUMO}

O objetivo deste artigo é analisar o discurso utilitarista sobre a aprendizagem da língua espanhola veiculado no texto Acuerdo cerrado, publicado em TAM nas Nuvens, revista de bordo da companhia aérea TAM. Os resultados da análise apontam para, basicamente, dois pré-construídos que parecem ancorar esse discurso utilitarista - a valorização da temporada no exterior como a melhor opção para acelerar o aprendizado do idioma e a suposta facilidade para aprender espanhol. Deste nosso ponto de vista, problematizar esse discurso utilitarista se torna imprescindível, já que este parece apenas (re)produzir práticas pedagógicas anacrônicas e pouco efetivas.

Palavras-chave: mídia; aprendizagem da língua espanhola; discurso utilitarista.

\section{ABSTRACT}

This paper provides an analysis of the utilitarian discourse about learning Spanish as a foreign language in the text Acuerdo cerrado, which was published by TAM nas Nuvens, the on-board magazine of the airline TAM. The results of the analysis suggest two preconceptions that seem to support that discourse: the value of the time spent in a foreign country as the best option to accelerate the learning of a foreign language and the supposed easy talk involved in learning Spanish. From our point of view, questioning this utilitarian discourse is essential because it seems to (re)produce outmoded and non-effective pedagogical practices.

Keywords: media; learning Spanish as a foreign language; utilitarian discourse.

* IFMT, Cuiabá (MT), Brasil. fernando_vesz@hotmail.com; UNEMAT, Cáceres (MT), Brasil. flaviakrauss@hotmail.com 


\section{INTRODUÇÃO}

O número de pesquisas que se voltam para questões sobre o espanhol no contexto brasileiro tem apresentado crescimento considerável nos últimos anos, principalmente aquelas que investigam ensino-aprendizagem (PARAQUETT, 2012). Entretanto, poucas ainda são as que buscam identificar os discursos que a mídia (re)produz sobre a inserção e o papel do espanhol na educação brasileira, principalmente após a homologação, em agosto de 2005, da Lei n. 11.161, que determina a oferta obrigatória do espanhol pela escola nos currículos plenos do ensino médio e também faculta a oferta do idioma ao ensino fundamental do $6^{\circ}$ ao $9^{\circ}$ ano.

Ao mesmo tempo, em virtude do crescimento da aviação no país, verificado principalmente nos últimos anos, mais e mais pessoas se habilitam ao acesso aos serviços oferecidos por esse setor. Dessa forma, as revistas de bordo das companhias aéreas ganham cada vez mais interesse da parte dos usuários. Seus textos, portanto, contribuem proporcionalmente para a (des)construção de diversas instâncias da vida social.

Neste artigo, analisamos o texto Acuerdo cerrado, escrito por Cynthia Costa e publicado na edição n. 55, julho de 2012, de TAM nas Nuvens, revista de bordo da companhia aérea TAM. A finalidade é identificar os pré-construídos que parecem ancorar o discurso utilitarista sobre a aprendizagem da língua espanhola veiculado em tal texto. Tomamos a noção de pré-construído, tal como desenhada por Paul Henry e delimitada por Pêcheux (2010, p. 89): aquilo que "remete a uma construção anterior, exterior, mas sempre independente, em oposição ao que é 'construído' pelo enunciado. Trata-se, em suma, do efeito discursivo ligado ao encaixe sintático". Já por discurso utilitarista, entendemos aquele que associa o ensino e a aprendizagem da língua a interesses meramente relacionados com o mercado de trabalho. Agasalha apenas objetivos instrumentais - aprender espanhol única e exclusivamente para definir novos rumos na carreira profissional, como se esse fosse o propósito germinal para a aprendizagem da língua.

Inicialmente, apresentamos a relação entre mídia e sociedade à luz da perspectiva proposta por Kellner (2001), ponto-chave para a proposta deste artigo. Em seguida, analisamos o referido texto. O que observamos é a reprodução e a manutenção desse discurso utilitarista em relação à aprendizagem do espanhol, identificado desde o nascimento do MERCOSUL (Mercado Comum do Sul), e ancorado em dois pré-construídos que envolvem o ensino e a aprendizagem de línguas estrangeiras no Brasil, a saber: a valorização da temporada no exterior e, no caso do espanhol, a facilidade para aprender a língua. 


\section{MÍDIA E SOCIEDADE}

De acordo com Kellner (2001), há uma cultura contemporânea dominada e veiculada pela mídia, que não apenas informa e/ou entretém, mas também contribui para nos ensinar como (não) nos comportar, o que (não) pensar, em que (não) acreditar, o que (não) desejar, etc. O autor afirma que a mídia é "[...] o lugar da cultura nas sociedades contemporâneas" (KELLNER, 2001, p. 54) e, portanto, seus textos não são simples veículos de uma ideologia dominante, mas produções complexas que incorporam discursos sociais e políticos em uma arena de lutas que os grupos sociais usam com o propósito de promover seus próprios programas e ideologias.

Essa cultura da mídia, segundo o autor, concorre para estabelecer a hegemonia de determinados grupos e projetos políticos, levando os indivíduos a ver, em certas ideologias, "o modo como as coisas são", ou seja, os textos culturais populares naturalizam e ajudam a mobilizar o consentimento a posições hegemônicas.

Entretanto, o autor ressalta que "[...] os textos devem ser lidos como expressão de várias vozes, e não como enunciação de uma única voz ideológica, que precise então ser especificada e atacada" (KELLNER, 2001, p. 148). Essas várias vozes, conforme o autor, são as contradições, os elementos contestatórios periféricos e os silêncios estruturados no texto que compreendem estratégias sobre, por exemplo, como o que é periférico pode ser tão significativo quanto o que é nuclear em termos de posições ideológicas, ou como elementos periféricos podem desconstruir posições ideológicas afirmadas no texto por contradizê-las ou enfraquecê-las, ou de que modo o não dito é tão importante quanto o que foi realmente dito.

Essa pedagogia crítica da mídia, como Kellner (2001) a define, visa, segundo o próprio autor, ao desenvolvimento da capacidade de "[...] discernir as mensagens, os valores e as ideologias que estão por trás dos textos da cultura da mídia" (KELLNER, 2001, p. 83), no sentido de perceber o modo como a cultura da mídia transmite representações que influenciam pensamentos e comportamentos. Esse discernimento e essa percepção possibilitam às pessoas, ainda no pensar do autor, um empoderamento em relação à cultura em que vivem, o que pode contribuir tanto para a promoção de questionamentos sobre a organização da sociedade quanto à participação dos indivíduos em movimentos políticos que se batem por transformações sociais. 


\section{O DISCURSO UTILITARISTA SOBRE A APRENDIZAGEM DA LÍNGUA ESPANHO- LA}

Como já mencionamos, o texto Acuerdo cerrado (p. 178-179) foi publicado em TAM nas Nuvens, revista de bordo da companhia aérea TAM. A referida edição é comemorativa da concretização da associação com a companhia aérea chilena LAN, dando origem ao grupo LATAM Airlines. O texto integra a seção Passaporte Corporativo (p. 177-184), definida como "seu caminho para o mundo das viagens a negócios" (p. 177).

Essa relação entre viagens e negócios pode ser observada no título - "negócio fechado", em espanhol - e é expandida no subtítulo do texto - "temporadas em países próximos são ideais para acelerar o aprendizado do espanhol e definir novos passos na carreira" (p. 178). Assim, o propósito para a aprendizagem do espanhol está associado a um discurso utilitarista sobre a língua, apresentado já no primeiro parágrafo do texto:

Há dois anos, o ensino do espanhol passou a ser obrigatório nas escolas de ensino médio brasileiras. O conhecimento dessa língua, que é a quarta mais falada do mundo e a segunda quando o assunto são negócios, tem sido cada vez mais exigido no mercado de trabalho (COSTA, 2012, p. 178).

Esse discurso utilitarista pode ser identificado desde o nascimento do MERCOSUL. Como apontam tanto Villa e del Valle (2008) quanto Paraquett (2009), o Acordo do MERCOSUL foi o impulso para o crescimento da demanda e da oferta do espanhol no Brasil. Esse primeiro momento sinalizava principalmente para o aspecto comercial do Acordo. Cox (1997), por exemplo, apontava o desejo e a necessidade do brasileiro dos anos 90 de bablar el español, pois, sob a égide do MERCOSUL, a nova geração de profissionais da área de marketing, comércio exterior, turismo, economia, etc. se sentia impelida a aprender o idioma. Dessa forma, a autora ressalta a motivação instrumental para estudar o idioma na década de 90, o que se deve, principalmente, às interações comerciais. "O que antes era visto como a língua de Quixote passou a ser visto como a língua do MERCOSUL", conclui.

Entretanto, voltando-nos novamente para o título do texto, percebemos que outras vozes, ainda que contraditórias, ressoam a partir da expressão acuerdo cerrado. Que acordo seria esse? Poderíamos pensar na própria lei n. 11.161 - ainda que a lei não seja exatamente um acordo, essa interpretação se sustenta a partir da primeira frase do texto, que se refere a um desdobramento direto da lei: "há dois anos, o ensino de espanhol passou a ser obrigatório nas escolas de ensino médio brasileiras" (COSTA, 2012, p. 178). Contudo, temos um indício de que esta é uma negociação 
de sentidos interditada, já que o acuerdo está cerrado - antes mesmo que ingressemos no texto, ela se apresenta desde o início como algo fechado.

A palavra cerrado, portanto, nos aponta para, pelo menos, duas interpretações possíveis: pode se referir tanto ao campo semântico dos negócios, como aludimos anteriormente (negócio fechado), quanto a um acordo no qual não é permitido participar na negociação, como se este já estivesse dado, objeto de decisão prévia. $\mathrm{O}$ acordo está fechado porque se reporta a uma exigência, uma interpelação para a qual não há escapatória que não a adaptação aos tempos, como se denota no primeiro parágrafo: "o conhecimento desta língua, que é a quarta mais falada no mundo e a segunda quando o assunto são negócios, tem sido cada vez mais exigido no mercado de trabalho" (COSTA, 2012, p. 178). Como se verifica, a função de língua veicular é a que mais sobressai na construção do enunciado - dizer que é a quarta língua mais falada no mundo serve somente como preparação do terreno para o dado mais importante, a saber, que é a segunda quando o assunto são negócios.

$\mathrm{O}$ discurso utilitarista sobre a aprendizagem do espanhol, nesse viés, parece estar ancorado em uma imagem que, no entender de del Valle (2007), a associa à sua condição de recurso econômico, ou seja, uma língua útil e rentável que pode constituir valioso capital cultural para quem a aprende. Essa imagem se indicia no texto a partir da bem-sucedida história do executivo Juliano Gonçalves.

Para o executivo Juliano Gonçalves, gerente da AES Eletropaulo, uma imersão de apenas duas semanas no Chile fez toda a diferença. "Eu vislumbrava uma transferência para os Estados Unidos. Já falava inglês e faltava o espanhol, pois faria a ponte entre os norte-americanos e os negócios na América Latina", conta. "Meses depois do intercâmbio em Santiago, concorri à vaga e consegui justamente por ter conhecimento do idioma". Juliano acabou trabalhando fora durante um ano e meio e teve a oportunidade de conhecer vários países, como Panamá, Argentina, El Salvador e República Dominicana (COSTA, 2012, p. 179).

Como é possível depreender, ter conhecimento desse valioso capital cultural - a língua espanhola - foi decisivo para Juliano conseguir a transferência que ambicionava. Ao mesmo tempo, o curso intensivo no Chile é apontado como o grande diferencial para o aceleramento do aprendizado da língua, (re)produzindo e reforçando a valorização da temporada no exterior e a adoração pelo que é estrangeiro (MOITA LOPES, 1996), neste caso tida como a melhor opção àqueles que desejam e/ou precisam acelerar o aprendizado do idioma para, como se apresenta no subtítulo do texto, "definir novos passos na carreira". Para esses, o intercâmbio na América do Sul representa a melhor opção: "passar uma temporada na Argentina ou em outro país da América do Sul é proveitoso, financeiramente acessível e prático - nem é preciso levar o passaporte" (COSTA, 2012, p. 178). São essas vantagens, 
principalmente, que tornam esses intercâmbios atraentes para aqueles que buscam aprimorar in loco o espanhol, privilegiando a carreira profissional.

De igual forma, para os brasileiros, essas vantagens podem ser ainda maximizadas.

\begin{abstract}
A boa notícia é que, para os brasileiros, o aprendizado costuma ser simples e ainda pode ser acelerado [...] "O brasileiro costuma chegar já em nível elementar ou intermediário, e melhora muito rápido quando se dedica", diz Marcia [Mattos, gerente de cursos da agência STB], que indica o programa de business ou as aulas "one-to-one" para quem procura o espanhol mais voltado para o trabalho. De fato, não é preciso passar meses afastado para obter avanços [...] Além disso, ficar em casa de família, sobretudo se a temporada for curta, pode ser a melhor opção, já que assim a convivência com o idioma e a cultura será intensificada (COSTA, 2012, p. 178-179).
\end{abstract}

Como vemos, "a boa notícia" consiste no pré-construído de que o espanhol é uma língua parecida com o português e, portanto, fácil para aprender. Esse pré-construído parece alinhavar todo o texto, oferecendo-lhe, inclusive, coesão. De acordo com Pêcheux (2010), constitui um efeito discursivo ligado ao encaixe sintático. Se não fosse por esse motivo, como explicar a abertura do texto, com menção à escola brasileira e à lei de obrigatoriedade de língua espanhola, e o desaparecimento desse tema no tecer do texto? A nosso ver, esse desaparecimento somente se justifica se levarmos em conta o fato de que existem, ao menos, outros dois pré-construídos - o de que não é necessário se submeter ao estudo formal para aprender a língua espanhola e o de que não se aprendem línguas estrangeiras na escola regular. Nesse vazio instaurado, entraria a viagem ao exterior.

Vale ressaltar que as aulas de língua espanhola, eventualmente frequentadas, figuram somente a título de alicerce que catalisa a construção do conhecimento que vai ser feita no estrangeiro, como aparece no excerto que retoma a bem-sucedida história do executivo Juliano Gonçalves: "é claro que, antes de viajar, Juliano já fazia aulas de espanhol, por isso seu aproveitamento foi maximizado" (COSTA, 2012, p. 179). Frequentar aulas de espanhol no Brasil seria o equivalente a tomar um acelerador metabólico antes do treino aeróbico: ajuda, acelera, mas sozinho não pode fazer nada. Assim, uma importante atitude a ser tomada ao chegar ao país estrangeiro é afastar-se da língua materna:

Manter-se longe do português foi importante. "Como as duas línguas são bastante semelhantes, é preciso evitar contato com outros brasileiros", ressalta Cristian Lema, sócio da agência Estude no Chile. Cristian desaconselha o intercâmbio nos meses de janeiro e julho, quando hordas de turistas brasileiros desembarcam em países sul-americanos (COSTA, 2012, p. 179). 
Além disso, as pessoas autorizadas a falar sobre ensino-aprendizagem da língua espanhola ao longo do texto não são professores, mas uma gerente de cursos e um sócio de agências de intercâmbios. Nem a escola, tampouco os professores ou a universidade, são convocados, em momento algum, para falar sobre ensino e aprendizagem da língua espanhola. Aprender espanhol parece se configurar, portanto, não como questão educacional, mas como questão de negócio.

Ainda sobre a facilidade para aprender espanhol, esta se ancora, de acordo com Lagares (2010), na prática de um ensino facilitado da língua, geralmente baseada apenas na simples listagem de palavras ou na comparação das diferenças lexicais com o português. Essa prática de ensino pode ser observada também na figura que ilustra o texto.

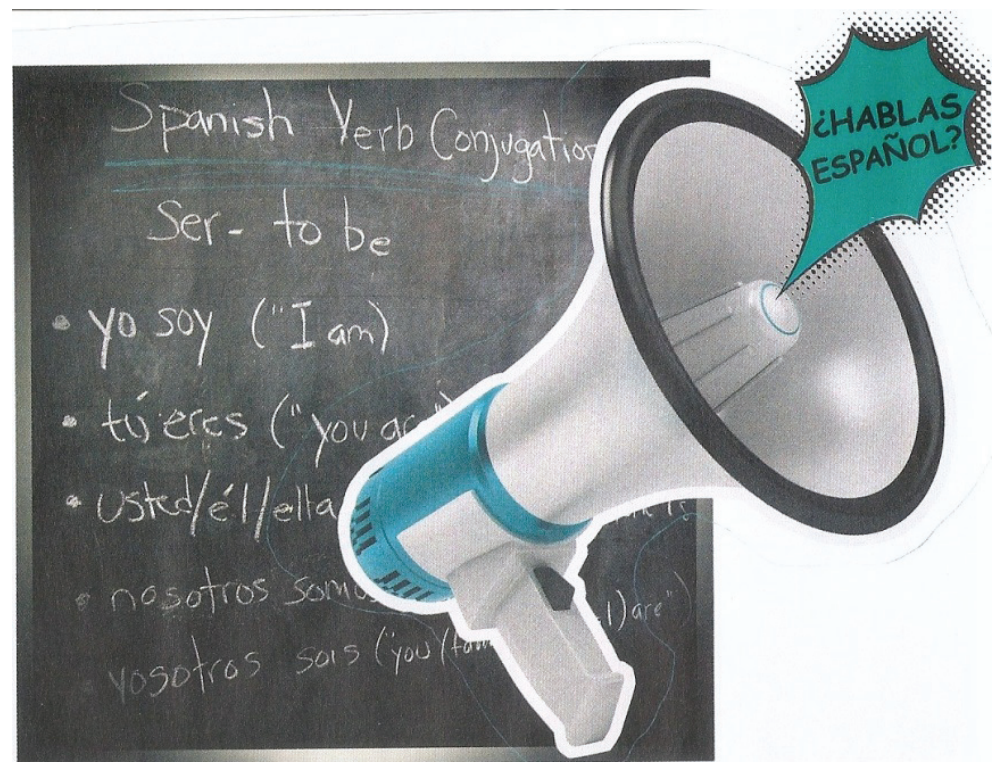

Figura 1. Imagem que ilustra o texto

Na figura, a fim de que se possa responder satisfatoriamente à pergunta emitida pelo alto-falante - ¿Hablas español? -, implicitamente se pressupõe que tão só o conhecimento da conjugação do verbo ser seria suficiente. A figura, portanto, aparece como uma metáfora de um modo de se ensinar língua espanhola, como se um fragmento da língua, estático no quadro-negro, fosse bastante, por si só, para o desenvolvimento da habilidade de fala dos aprendizes. 
Em suma, o discurso utilitarista sobre o espanhol se assenta, no texto, como já destacamos, basicamente em dois pré-construídos. Um que envolve o ensino e a aprendizagem de línguas estrangeiras no Brasil, a saber, a valorização da temporada no exterior como a melhor opção, neste caso, para acelerar o aprendizado do idioma e definir novos rumos na carreira profissional. $\mathrm{O}$ outro, relacionado com o primeiro, encarta a suposta facilidade para aprender espanhol, sendo desnecessário passar meses no país escolhido para obter resultados positivos - "o aprendizado costuma ser simples" (COSTA, 2012, p. 178).

\section{¿ACUERDO CERRADO?}

Como apresentamos já na introdução deste artigo, os textos das revistas de bordo das companhias aéreas se tornam cada vez mais lidos, contribuindo, dessa forma, proporcionalmente para a (des)construção de diversas instâncias da vida social. Portanto, o texto Acuerdo cerrado, publicado na revista de bordo da companhia aérea TAM, atribui determinados sentidos ao ensino e à aprendizagem do espanhol que, como afirma Kellner (2001), contribuem para vermos neles "o modo como as coisas são".

Como afirma o texto já em seu primeiro parágrafo - "há dois anos, o ensino do espanhol passou a ser obrigatório nas escolas de ensino médio brasileiras" (p. 178), pensamos caber aqui a pergunta: qual a finalidade da homologação de uma lei que obriga a oferta da língua espanhola nas escolas em nosso país? Não acreditamos que a resposta seria a manutenção desse discurso utilitarista da língua ancorado em pré-construídos que apenas proporcionam a continuação de práticas pedagógicas anacrônicas e pouco efetivas - um ensino facilitado da língua, geralmente baseado apenas na simples listagem de palavras ou na comparação das diferenças lexicais com o português, ou ainda a valorização da temporada no exterior e a adoração pelo que é estrangeiro.

Propomos, em conclusão, "fechar um acordo" em relação à finalidade da obrigatoriedade da oferta da língua: que aprender espanhol envolva uma visão menos reducionista, desatrelada do imediatismo do MERCOSUL ou do mercado de trabalho. Em complemento, que entenda a aprendizagem de línguas não apenas circunscrita a seus objetivos instrumentais, mas como parte da formação integral do aluno, colaborando para desarticular os pré-construídos que discutimos ao longo deste artigo. Acreditamos que tal caminho pode nos conduzir a (re)discutir o papel da língua espanhola no contexto brasileiro em direção a um ensino mais significativo. ¿Acuerdo cerrado? 


\section{REFERÊNCIAS BIBLIOGRÁFICAS}

COSTA, C. (2012). Acuerdo cerrado - temporadas em países próximos são ideais para acelerar o aprendizado do espanhol e definir novos passos na carreira. TAM nas Nuvens, ano 5, n. 55, pp. 178-179.

COX, M. I. P. (1997). A hora e a vez do espanhol... Revista de Educação Pública, v. 6, n. 10.

DEL VALLE, J. (2007). La lengua, patria común: la hispanofonía y el nacionalismo panhispánico. In: DEL VALLE, J. (ed.) La lengua, patria común? - ideas e ideologías del español. Madri/Frankfurt am Main: Iberoamericana/Vervuert, pp. 31-56.

KELLNER, D. (2001). A cultura da mídia - estudos culturais: identidade e política entre o moderno e o pós-moderno. Bauru: EDUSC.

LAGARES, X. C. (2010). A ideologia do panhispanismo e o ensino do espanhol no Brasil. Políticas Lingüísticas, n. 2, v. 2, pp. 85-110.

MOITA LOPES, L. P. (1996). Oficina de linguística aplicada - a natureza social e educacional dos processos de ensino-aprendizagem de línguas. Campinas: Mercado de Letras.

PARAQUETT, M. (2009). O papel que cumprimos os professores de espanhol como língua estrangeira (E/LE) no Brasil. Cadernos de Letras da UFF, n. 38, pp. 123-137.

. (2012). A língua espanhola e a linguística aplicada no Brasil. Abebache, ano 2, n. 2, pp. 225-239.

PÊCHEUX, M. (2010). Semântica e discurso - uma crítica à afirmação do óbvio. Campinas: Editora da Unicamp.

VILLA, L.; DEL VALLE, J. (2008). iOye!: língua e negócio entre o Brasil e a Espanha. São Leopoldo: Calidoscópio, v. 6, n. 1, pp. 45-55. 


\section{Anexo 1}

\section{Acuerdo cerrado}

Temporadas em países próximos são ideais para acelerar o aprendizado do espanhol e definir novos passos na carreira

\section{Por Cynthia Costa}

Há dois anos, o ensino do espanhol passou a ser obrigatório nas escolas de ensino médio brasileiras. O conhecimento dessa língua, que é a quarta mais falada no mundo e a segunda quando o assunto são negócios, tem sido cada vez mais exigido no mercado de trabalho. A boa notícia é que, para os brasileiros, o aprendizado costuma ser simples e ainda pode ser acelerado: passar uma temporada na Argentina ou em outro país da América do Sul é proveitoso, financeiramente acessível e prático - nem é preciso levar o passaporte.

"A busca por intercâmbios na América do Sul aumentou 50\% nos últimos anos", revela Marcia Mattos, gerente de cursos da agência STB, que oferece inclusive programas mais longos, como a pós-graduação em culinária em Cusco, no Peru. Os mais procurados, porém, são os intensivões de quatro a seis semanas, combinados ou não com aulas temáticas. Na Argentina, por exemplo, a experiência ganha os contornos desejados pelo aluno: pode-se desbravar a Terra do Fogo durante um mês de estudos em Ushuaia ou alugar um apartamento no descolado bairro portenho de Palermo, bem próximo à escola. $\mathrm{O}$ importante, claro, é o resultado. "O brasileiro costuma chegar já em nível elementar ou intermediário, e melhora muito rápido quando se dedica", diz Marcia, que indica o programa de business ou as aulas "one-to-one" para quem procura o espanhol mais voltado para o trabalho.

De fato, não é preciso passar meses afastado para obter avanços. Para o executivo Juliano Gonçalves, gerente da AES Eletropaulo, uma imersão de apenas duas semanas no Chile fez toda a diferença. "Eu vislumbrava uma transferência para os Estados Unidos. Já falava inglês e faltava o espanhol, pois faria a ponte entre os norte-americanos e os negócios na América Latina", conta. "Meses depois do intercâmbio em Santiago, concorri à vaga e consegui justamente por ter o conhecimento do idioma". Juliano acabou 
trabalhando fora durante um ano e meio e teve a oportunidade de conhecer vários países, como Panamá, Argentina, El Salvador e República Dominicana.

É claro que, antes de viajar, Juliano já fazia aulas de espanhol, por isso seu aproveitamento foi maximizado. Na capital chilena, hospedou-se na casa de uma família e ingressou no curso no nível intermediário. Manter-se longe do português foi importante. "Como as duas línguas são bastante semelhantes, é preciso evitar contato com outros brasileiros", ressalta Cristian Lema, sócio da agência Estude no Chile. Cristian desaconselha o intercâmbio nos meses de janeiro e julho, quando hordas de turistas brasileiros desembarcam em países sul-americanos. Além disso, ficar em casa de família, sobretudo se a temporada for curta, pode ser a melhor opção, já que assim a convivência com o idioma e a cultura será intensificada. Nas escolas, onde as aulas costumam ter duração de quatro a cinco horas por dia, o ideal é fazer amizade com estrangeiros. "Recentemente, percebemos o crescimento do número de estudantes norte-americanos e europeus aqui na América do Sul", observa.

Recebido: 03/05/2013

Aceito: 04/10/2013 
